\title{
Burn Care in Kirtipur Hospital before and during COVID 19 Pandemic: Survey of Psychological Issues and Practice Behaviours of Burn Care Personnel
}

\author{
KK NAKARMI, SJ BASNET, B KARKI, M GHARTIMAGAR, KK NAGARKOTI, MK YADAV, SM RAI
}

\begin{abstract}
:
Introduction: The COVID 19 pandemic has adversely impacted all aspects of health care throughout the world. Burn care in lower and middle income countries has suffered the most. We aimed to compare burn care at Kirtipur Hospital before and during the pandemic and explore psychological issues and practice behaviour among burn care worker $(\mathrm{BCW})$.
\end{abstract}

Methods: Retrospective data analysis of burn patients admitted during April to August of 2019 and 2020 was done. Internet based survey of $B C W$ was done.

Results: Burn admissions, demographics and characteristics did not change. Fewer surgeries were undertaken in 2020.

Almost half of the BCW worked 12 hours shift or longer. Most were working on half pay. Nearly everyone was using

\section{Introduction:}

More than $95 \%$ of fire related burn injuries occur in the low and middle income countries (LMIC). It leads to more than 300,000 deaths every year of which half is attributed to Southeast Asia alone (1). Management of burns is challenging as the treatment is lengthy and demands a dedicated team management. Furthermore, it is expensive and often financially catastrophic for the already impoverished patients from LMICs (2-4); and is often neglected in these countries even in normal conditions (5). Sudden emergence of COVID 19 pandemic has adversely affected resource management throughout the world even in high income countries (6). This particularly impacted burn care (7). The effect could be detrimental in already resource scarce countries.

Department of Burns, Plastic and Reconstructive Surgery, Nepal Cleft and Burn Center Phect-NEPAL, Kirtipur Hospital, Kathmandu, Nepal

Address of Correspondence: Kiran K. Nakarmi, Department of Burns, Plastic and Reconstructive Surgery, Nepal Cleft and Burn Center Phect-NEPAL, Kirtipur Hospital, Kathmandu, Nepal, Phone: +977-9851061490, Email: kknakarmi@yahoo.com

Receive: 21 December, 2020

Accept : 26 June, 2021 hand sanitizers, hand washing and masks. Few had access to level II personal protective equipments (PPE) to see suspected patients; fewer had access to face shield, KN 95 masks and boot. Even gloves and caps were scarce. Many feared getting themselves or family members infected. Majority realized the need of clear hospital policy on how they would be managed when infected.

Conclusion: Number, types, severity and mortality did not change. Number of surgeries decreased. Issues like pay cuts, longer working hours and lack of PPEs were reported by majority.

Keywords: Burn, burn care personnel, corona pandemic, COVID 19, PPE

(J Bangladesh Coll Phys Surg 2021; 39: 241-248)

DOI: https://doi.org/10.3329/jbcps.v39i4.55945

Kirtipur Hospital is a high volume burn center which routinely receives patients from all over the country and neighbouring Indian states. While the lockdown has severely restricted the movement of individuals, Kirtipur Hospital continues to receive high volume of patients; especially as other burn centers in the city are admitting fewer burn patients than usual due to need of resource redistribution to take care of COVID 19 patients.

Initially, a decrease in the number of patients allowed us to cohort our burn care worker (BCW) to minimize exposure; however, lack of resources has forced us to work in relatively unsafe environment with extremely limited access to adequate personal protective equipment (PPE). This increases the risk not only to $\mathrm{BCW}$ but also patients and families. Patient families are at risk of contracting COVID 19 infection from other patients and families due to shared facilities in the common wards. Patients are particularly vulnerable due to impaired immune function in the setting of major burn injury.

The hospital has adopted a policy of testing the burn patients before admission. Initially, rapid diagnostic test 
(antibody) was done to all the patients (Figure 1); later polymerase chain reaction (PCR) test was made mandatory for all the patients (Figure 2). Hospital has also adopted the policy of allowing only two family members per family and mask to all the patients and families to reduce the cross infection. However PCR test is not available in our hospital. Nasopharyngeal swab was taken by the laboratory staff only during a one hour window (9-10 AM) and sent to nearby laboratory. It took us between 6 hours to few days to get the report back depending on the load of samples. Until then, patient and family were kept in the observation facility and emergency treatment such as fluid resuscitation and dressing were allowed. Only few patients required escharotomy/fasciotomy while report was still pending. Once the report was negative then they would be transferred to the burn ward and prepared for surgery in the next available operating day.

Number of operative sessions was reduced from 6 to 2 a week. Only emergency or semi emergency cases were done and number of procedures per patient was limited as much as possible. Use of allograft completely stopped as allograft harvesting without proper testing of the donors and protection of the harvesting personnel could increase the risk of transmission of infection (8). Electric dermatome was not used inside the operating theater due to the risk of aerosol generation $(9,10)$.

Endotracheal intubation was not practised as much as possible for the fear of aggravating respiratory complication in case of undetected COVID 19 infection in the patients and also to protect the anesthesia personnel who were forced to intubate with only face shield and surgical masks (11). Intubation glass chamber is not available in the hospital.

Given the challenges noted and described above at Kirtipur Hospital in response to COVID 19 pandemic, we thought to understand the impacts of the challenges and adjustments. The aim of this study was to investigate the demography and outcome of burn patients along with changes in the practice and behaviour of BCWs involved.

\section{Methods:}

Ethical approval was obtained from Institutional Review Committee of phect-NEPAL.

A retrospective cohort analysis of the burn injured patients admitted to Kirtipur Hospital during the period of April to August in the year 2019 and same duration in 2020 was done. Demographic and outcome data as the number of admitted patients, patient demographics, burn characteristics and outcome were described and compared.

Additionally, a structured questionnaire was used to understand the BCW demographics, academic background, clinical role, workload, payment status, psychological concerns and occupational health issues in the light of the COVID 19 pandemic. The survey was voluntary, and was administered via a confidential and secure internet based platform.

\section{Results:}

Patient evaluation: A total of 192 and 139 patients were admitted in 2019 and 2020 respectively $(p=0.57)$. Figure 3 shows the monthly distribution of admitted burn patients during the period. Most of the months in 2019 had more patients but there were more patients in the month of July 2020.

There were more males (60\% vs. 58\%) in both 2019 and 2020. More than one third of the patients belonged to the age group 5-15 years, however most belonged to 15-60 years of age group. There was slight increase in flame burn and electric burn. Scald burn decreased significantly $(\mathrm{p}=0.01)$ (Table 1$)$.

\section{Burn Injury Characteristics and Outcomes:}

Extent of burn and mortality were similar before and after COVID 19 (Table 2). There were $58 \%$ of patients receiving one session of excision and grafting in 2019 vs. $27 \%$ in $2020(p=0.1)$. Less than four per cent of the patients underwent two or more sessions of excision and grafting in both 2019 and 2020. Significantly higher (8 vs. 5\%) proportion of patients left hospital left hospital against medical advice in $2019(\mathrm{p}=0.04)$. Out of the seven patients who left hospital in 2020, two were transferred to COVID 19 hospitals for further management because they had tested positive for virus.

\section{Survey on the $B C W$ :}

Thirty seven out of $75 \mathrm{BCW}$ responded to the questionnaire survey.

i) Demographics: Sixty eight percent were females. Most belonged to the age group 20-30 years (Figure 4).

ii) Clinical role: Most of the respondents were the nurses/health assistants and worked in burn operating rooms (OR). Most of them had graduate level education (Table 3 ). 
Table-I

Patient demographics and causes of burn

\begin{tabular}{|c|c|c|c|c|c|c|c|c|c|c|}
\hline \multirow[t]{2}{*}{ Year } & \multirow{2}{*}{$\begin{array}{c}\text { Total } \\
\text { Patients }\end{array}$} & \multicolumn{2}{|c|}{ Gender } & \multicolumn{3}{|c|}{ Age Group (Year) } & \multicolumn{4}{|c|}{ Etiology } \\
\hline & & Male & Female & $0-15$ & $15-60$ & $60+$ & Flame & Scald & Electric & Others \\
\hline 2019 & 192 & 115 & 77 & 70 & 107 & 15 & 91 & 59 & 34 & 8 \\
\hline 2020 & 139 & 81 & 58 & 55 & 77 & 7 & 75 & 31 & 30 & 3 \\
\hline Total & 331 & 196 & 135 & 125 & 184 & 22 & 166 & 90 & 64 & 11 \\
\hline
\end{tabular}

Table-II

\begin{tabular}{lccc} 
& \multicolumn{2}{c}{ Extent and mortality of burn } \\
Year & TBSA of all patients (range) & Mortality $(\%)$ & TBSA of deceased patients \\
\hline 2019 & $20 \%(1-85)$ & 20 & $20 \%(10-85)$ \\
2020 & $18 \%(1-90)$ & 18 & $18 \%(10-90$ \\
P value & 0.16 & 0.1 & 0.16 \\
\hline
\end{tabular}

Table-III

\begin{tabular}{|c|c|c|c|c|c|c|c|c|c|}
\hline \multicolumn{10}{|c|}{ Qualification and job role } \\
\hline \multicolumn{3}{|c|}{ Qualification (\% of BCW) } & \multicolumn{3}{|c|}{ Job role $(\%$ of $\mathrm{BCW})$} & \multicolumn{4}{|c|}{ Working station ( $\%$ of BCW) } \\
\hline $\begin{array}{l}\text { Post } \\
\text { graduate }\end{array}$ & Graduate & $\begin{array}{l}\text { Higher } \\
\text { school }\end{array}$ & $\begin{array}{c}\text { Plastic } \\
\text { Surgeons }\end{array}$ & $\begin{array}{l}\text { Nurse } \\
\text { / HA }\end{array}$ & $\begin{array}{l}\text { CMA/ } \\
\text { ANM }\end{array}$ & $\begin{array}{l}\mathrm{O} \\
\mathrm{R}\end{array}$ & $\begin{array}{l}\text { Burn } \\
\text { ward }\end{array}$ & $\begin{array}{l}\text { Other } \\
\text { ward }\end{array}$ & $\begin{array}{c}\text { Burn } \\
\text { ICU }\end{array}$ \\
\hline 27 & 41 & 24 & 16 & 51 & 8 & 38 & 21 & 16 & 13 \\
\hline
\end{tabular}

Table-IV

Workload

\begin{tabular}{|c|c|c|c|c|c|c|c|c|c|c|c|c|c|}
\hline \multicolumn{3}{|c|}{$\begin{array}{c}\text { Perceived number } \\
\text { of patients }\end{array}$} & \multicolumn{4}{|c|}{ Workload } & \multicolumn{4}{|c|}{ Work days per week } & \multicolumn{3}{|c|}{ Shift (hours) } \\
\hline $\begin{array}{l}\mathscr{2} \\
\stackrel{0}{0} \\
0 \\
0 \\
0 \\
0 \\
0 \\
0 \\
0 \\
0\end{array}$ & 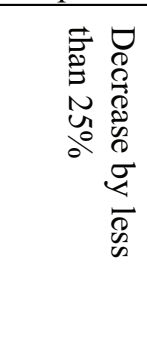 & 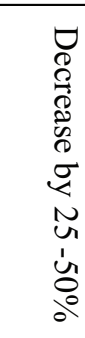 & 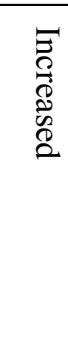 & 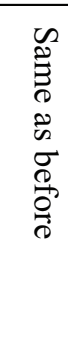 & 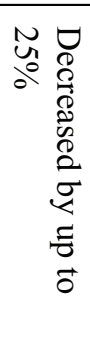 & 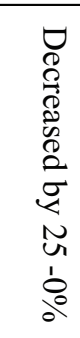 & 3 & 4 & 5 & 6 & $6-8$ & $8-12$ & $12+$ \\
\hline 39 & 22 & 25 & 24 & 22 & 27 & 22 & 19 & 38 & 13 & 27 & 43 & 30 & 16 \\
\hline
\end{tabular}



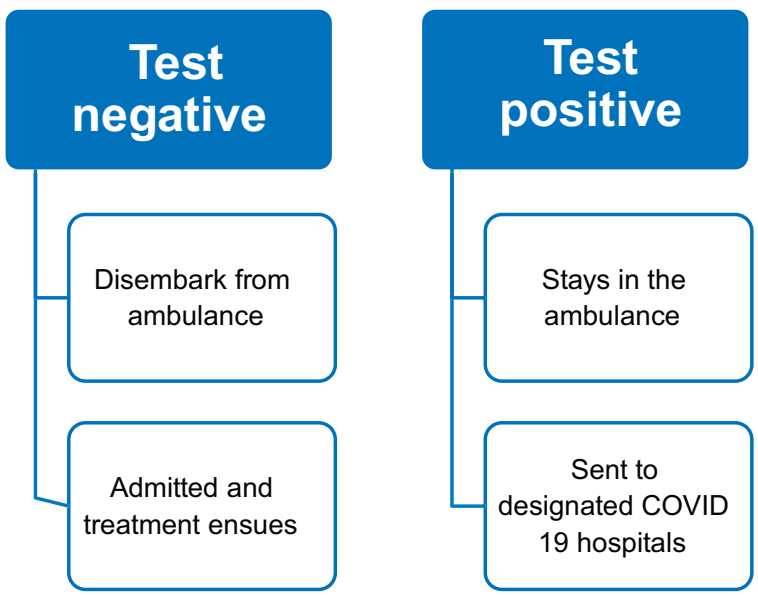

Fig.-1: Flow chart during initial lockdown period when only antigen test was available

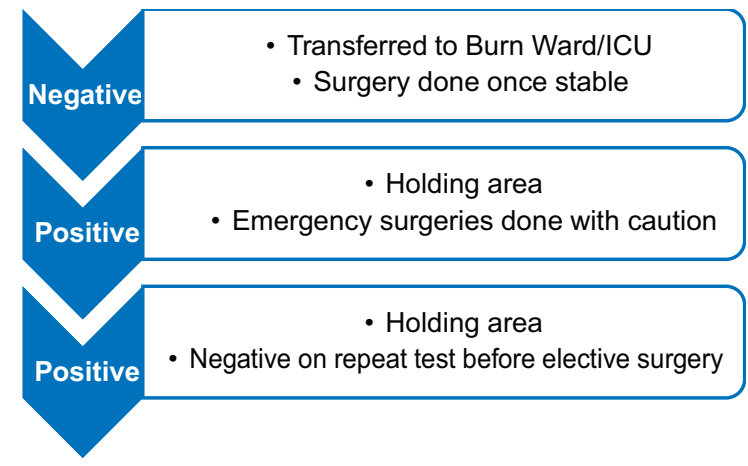

Fig.-2: Flow chart during the later part of lockdown with PCR test available

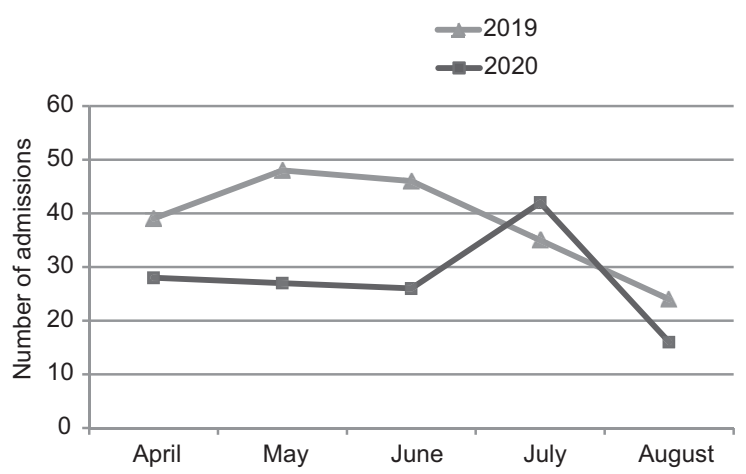

Fig.-3: Monthly distribution of burn admissions

Thirty eight percent of the respondents had been working for 2-5 years after qualification, $22 \%$ for 1 2 years, $14 \%$ for $5-10$ years, $11 \%$ since $15-20$ years and $8 \%$ for less than one year. Thirty four percent

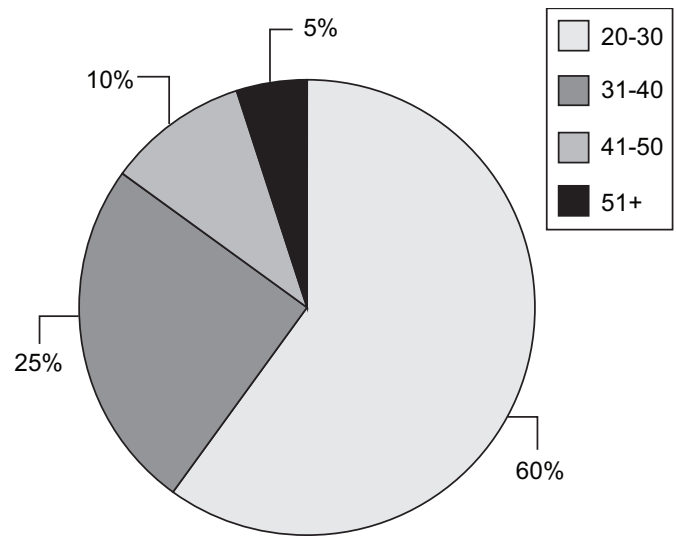

Fig.-4: Age distribution of burn care personnel (BCP)

started seeing burn patients since 2-5 years, 23\% since less than a year, $17 \%$ since $1-2$ years and $5-10$ years.

Fifty eight percent of the respondents admitted that more than three fourth of their practice consisted of burn care, $14 \%$ had half to three fourth of their practice consisting burn care. Forty percent of the respondents were happy to be able to help burn patients, $30 \%$ found the job okay, $11 \%$ each of the respondents either felt positive or inspired about their job. Overall, $92 \%$ of the respondents were happy with their job. Despite that most of the BCWs were not happy with their pay $(79 \%)$ and equal number was unhappy because of bad outcome of patients and professional insecurity (38\%).

iii) Workload: Most felt that the number of patients had remained the same and workload remained the same or increased. Most BCW worked 4 days a week and 6-8 hours shifts (Error! Reference source not found.). Almost $58 \%$ of the respondents were getting half salary, $31 \%$ were getting three fourth salary and only $11 \%$ were getting full salary.

iv) Psychological concerns: Most common concern during this pandemic was transmitting infection to the family members (76\%), getting themselves infected $(65 \%)$, getting pay cuts $(54 \%)$, discrimination from the landlord, neighbors or the society $(38 \%)$ and fear of death of family and relatives $(30 \%)$.

v) Virtual trainings: Half of the respondents took part in the virtual educations similar to or more than 
before the lockdown. Another one fourth did not know about such trainings. Most wanted to hear about issues such as psychological and professional security (69\%) and other more relevant topics (58\%), half of them wanted more interactive sessions. Fifty three percent of the respondents who did not attend such trainings reported this was due to being busy at work.

vi) Safety measures adopted after the lockdown: Most common behavioral changes involved use of mask and hand washing in $97 \%$ of the cases, use of sanitizer in $95 \%$, avoidance of shaking hands and hugging $(78 \%)$ and use of PPE (43\%). Twenty nine percent of them had access to standard PPE with face shield and shoe-covers to see COVID 19 suspected patients, $40 \%$ had access to locally made and sterilizable level II PPE, 26\% had only mask and gloves while another $6 \%$ had only regular cloth gown. KN 95 mask was the most widely used mask (62\%), followed by surgical mask (32\%) and N 95 (5\%). Most of the respondents bought the mask themselves (72\%), 14\% were provided by hospital and $11 \%$ were bought by the patient families. Mask was changed once a week by $35 \%$ of the respondents, $2-3$ times a week by $32 \%, 22 \%$ of the respondents got new mask every time they were in hospital, 11\% did not change mask until they got a new one. Outside the operation theater, unsterile gloves were used most of the times (86\%) out of which $19 \%$ were recycled.

vii) Occupational health: Most of the respondents were not clear about hospital protocol regarding management of health care worker in case of work related infection. Forty nine percent of the respondent felt that they would be sent to home quarantine if they got infected, $35 \%$ had no idea what would happen to them, $32 \%$ thought PCR test would be done to them, $24 \%$ thought they would be sent to isolation and 3\% thought they would be laid off. Out of $15 \mathrm{BCW}$ who had either suspicion or diagnosis of COVID 19 infection, 10 had PCR test, 3 were sent to home quarantine and 2 (who positive) were sent to isolation. All recovered in the end.

\section{Discussion:}

Given that burn patients can also have or acquire asymptomatic COVID 19 infection treating patients based on an initial negative test result without proper protection can risk both patients and staff. Significant presence of false negative tests should always be taken into consideration and universal protective measures should be taken ${ }^{12,13}$. High risk procedures in suspected COVID 19 burn patients include establishing intravenous access, endotracheal intubation or tracheostomy, wound treatment, and surgery. The implementation of effective, appropriate-grade protection and development of practical treatment procedures are necessary to protect $\mathrm{BCWs}^{14}$.

Contrary to the reports from other parts of the world (15), number of burn admissions did not decrease significantly in our center. The community burn incidence might be increasing due to increase in domestic burns in our set up as people are forced to spend more time at home due to the national lockdown. It is probably reflected better in places where mobility of patients is not restricted ${ }^{16}$. Decrease in the mobility may have resulted in slight decrease in the number of despite hypothetical increase in the incidence. Increase in the number of admissions in the month of July can be related to the partial lift off of the lockdown in the country allowing movement of patients from different parts of the country to our hospital. It may also be related to the fact that other centers that typically also care for burn patients are busy taking care of COVID 19 cases $^{17}$.

Most literature from LMIC demonstrate higher incidence of burns in female patients and adults are the most commonly involved age group ${ }^{18,19}$. Earlier reports from our center also showed female prevalence ${ }^{20,21}$. However, the shift towards increased male prevalence was noticed both immediately before and during pandemic. Commonest age group of our patients is similar to other studies and there was no change during the pandemic. No increase in incidence of burn in pediatric age group was seen as reported elsewhere ${ }^{16}$. Flame burn was the commonest cause of burn in our study which is similar to other reports from our center and elsewhere ${ }^{18-23}$ Scald seemed to decrease significantly in our study. This may be attributed to the fact that most of the scald burns were either not extensive or likely to be managed locally or in outpatient. This could also be due to more stringent admission criteria.

No significant difference in average TBSA was seen before and during pandemic. This is expected as the 
etiology of burn remained the same. The number of procedures per patient was kept to minimum. Only emergency and semi emergency cases were taken to the operation theater. Similar trend has been seen or recommended from other centers ${ }^{7,13,24}$. Mortality rate was also unchanged before and after the pandemic. Our hospital was not involved in taking care of COVID 19 infected burn patients. Two of the admitted burn patients with positive tests were referred to COVID 19 hospitals. Fewer patients left hospital against medical advice probably in association with decreased mobility due to the national lockdown. This trend is seen also during normal circumstances.

One third of the BCW respondents had spent 2-5 years caring for burn patients. This coincides with the fact that the hospital started its burn service 6 years back. Almost three fourth of the respondents devoted half to three fourth of their time in taking care of burn patients; this is not unusual in a place which is a multispecialty hospital. More than $90 \%$ of the respondents were happy with their job despite the fact that almost $80 \%$ felt that their pay was inadequate. Almost a quarter of BCWs felt overworked after the lockdown due to staff cut down (cohorting) and long working hours. Only 27\% worked 6 days a week however 30\% worked 8-12 hours shift while $16 \%$ worked more than 12 hours a day. Fifty eight percent of the BCWs were getting half the salary and $31 \%$ were getting three fourth the salary. These factors along with the need to work with potential COVID 19 patients can lead to psychological burn out in the BCWs as shown elsewhere ${ }^{25-27}$. Same is true for the burn care doctors $^{28}$.

Fear and psychological stress has been found across the general population ${ }^{29}$. Most common concern among our study population was fear of transmitting infection to the family member (76\%) or themselves $(65 \%)$. Half of them feared ongoing salary reduction and one third were worried about discrimination from the society. Fear of death was also present in one third of the BCWs. Fear has been demonstrated in frontline Filipino nurses taking care of COVID 19 patients. Increased level of fear has been associated with increased psychological stress, job satisfaction and increased turnover intention ${ }^{30}$.

Only half of the respondents in our study participated in ongoing virtual trainings; the remaining half either cited a lack of availability or lack of awareness of the training. Significant proportion of BCWs $(60-70 \%)$ wanted these meetings to address issues such as psychological and professional security as shown in other study ${ }^{31}$. Virtual trainings and recordings may be a reasonable and accessible format for $\mathrm{BCW}$ to receiving additional psycho-social training and support.

Most common behavioral change after the lockdown was use of sanitizers and hand washing by almost all of the BCWs. Physical distancing measures such as avoidance of hugging shaking of hands were brought into practice by more than three fourth. Less than a third had access to standard PPE with face shield, KN 95 mask and boot to see a COVID 19 suspected patient. Locally made sterilizable level II PPE was being used by $40 \%$ of the BCWs during surgery and dressing changes. Access to masks was limited and they were being used for longer than recommended ${ }^{32}$. Unsterile gloves were used in most instances (86\%) except surgery and they were being recycled in $11 \%$ of the cases. Recycling was not done previously in our center. Recycling of gloves was started because of its positive environmental and economic implications as reported by Choudhury ${ }^{33}$.

\section{Limitations of the study:}

We were able to enroll less than half of the $\mathrm{BCW}$ despite keeping the questionnaire simple and anonymous. Most of them were young, well educated and more likely to respond to internet based survey than their older colleagues. The study focuses only on the first five months when the lockdown was enforced more rigorously. It does not represent the winter months when most burn patients come to our center. However, we also took the same period of time from the last year for comparison.

\section{Conclusion:}

Number of admissions and etiology of burns remained the same. TBSA of burn and mortality also remained same. Surgery was being done less frequently to avoid anesthesia related complications to the patients and also to decrease the rate of transmission to the BCWs. Out of hospital transfer of patients also reduced. Most of the BCWs were adopting hand washing and use of sanitizers; physical distancing measures were being practiced. Gross shortage of PPE and masks was noted by most. Most of the BCWs were overworked and underpaid after the lockdown leading to psychological burn down and occupational insecurity. Most were 
worried about getting themselves or their family members infected; some feared death and discrimination. Only half participated in virtual trainings and they wanted psychological and occupational issues to be addressed in such trainings.

\section{Recommendations:}

The current pandemic appears it will be a presence and reality for many months if not years. We have to take it as a new normal and learn to live with it. In a time when health care facilities are suffering economic crisis like other sectors (34-36), the constant flow of burn patients provides unique opportunity not only to provide care to maximum number of patients which is not available in other facilities due to the pandemic but also helps to financially support the institution. This in turn will help pay the $\mathrm{BCW}$ and reduce the risk of lay off. However, in order for the burn care system to continue to function, the need of $\mathrm{BCW}$ and patients along with their families has to be addressed well. It can be done through implementation of proper safety protocol and availing standard PPE at commonly needed locations. BCW also need psychological support besides adequate pay and safety measures to enhance the output. Psychological support can be achieved through frequent virtual trainings and appropriate levels of encouragement by the colleagues and authority.

Conflict of interest:

The authors have no conflict of interest.

\section{Acknowledgements:}

All the colleagues who participated in the survey deserve a special thank.

\section{References:}

1. Peck M, Molnar J, Swart D. A global plan for burn prevention and care. Bull World Health Organ. 2009 Oct 1;87(10):8023. https://doi.org/10.2471/BLT.08.059733 PMid:19876549 PMCid:PMC2755313

2. Davé DR, Nagarjan N, Canner JK, Kushner AL, Stewart BT. Rethinking burns for low \& middle-income countries: Differing patterns of burn epidemiology, care seeking behavior, and outcomes across four countries. Burns. 2018 Aug;44(5):1228-34. https://doi.org/10.1016/j.burns.2018. 01.015 PMid:29475744

3. Peck MD. Epidemiology of burns throughout the World. Part II: Intentional burns in adults. Burns. 2012 Aug;38(5):630-7. https://doi.org/10.1016/j.burns.2011. 12.028 PMid:22325849

4. Koljonen V, Laitila M, Rissanen AM, Sintonen H, Roine RP. Treatment of Patients With Severe Burns-Costs and Health-Related Quality of Life Outcome: J Burn Care Res. 2013;34(6):e318-25. https://doi.org/10.1097/BCR.0b013e 3182779c90 PMid:23702860

5. Tripathee S, Basnet SJ. Epidemiology of burn injuries in Nepal: a systemic review. Burns Trauma. 2017 Dec 1;5:s41038-017-0075-y. https://doi.org/10.1186/s41038017-0075-y PMid:28413803 PMCid:PMC5389177

6. Kamolz L-P, Schiefer JL, Horter J, Plock JA. COVID-19 and burns: Lessons learned? Burns. 2020 Sep;46(6):1467-8. https://doi.org/10.1016/j.burns.2020.05.015 PMid: 32536450 PMCid:PMC7255706

7. Barret JP, Chong SJ, Depetris N, Fisher MD, Luo G, Moiemen N, et al. Burn center function during the COVID19 pandemic: An international multi-center report of strategy and experience. Burns. 2020 Aug;46(5):1021-35. https://doi.org/10.1016/j.burns.2020.04.003 PMid: 32416984 PMCid:PMC7151262

8. Paggiaro AO, Conceição RO, Bianchi MP, Gemperli R. COVID-19 and risk management in a tissue bank. Clinics. 2020;75:e2132. https://doi.org/10.6061/clinics/2020/ e2132 PMid:32667490 PMCid:PMC7337216

9. Noblet TM, Jivan S, Anwar MU. Safety of powered dermatome during the COVID-19 pandemic. Burns. 2020 Jul;S030541792030471X. https://doi.org/10.1016/ j.burns.2020.07.012 PMid:32762960 PMCid:PMC7382924

10. Shokrollahi K, Kyriazidis I, Zak-Williams S, Jones C, Murgatroyd E, Gurusinghe D. Is the use of a powered dermatome an aerosol-generating procedure (AGP)? Implications for personal protection against COVID-19 virus. Scars Burns Heal. 2020 Jan;6:205951312095192. https://doi.org/10.1177/2059513120951920

11. Brewster DJ, Chrimes N, Do TB, Fraser K, Groombridge CJ, Higgs A, et al. Consensus statement: Safe Airway Society principles of airway management and tracheal intubation specific to the COVID 19 adult patient group. Med J Aust. 2020 Jun;212(10):472-81. https://doi.org/10.5694/ mja2.50598 PMid:32356900 PMCid:PMC7267410

12. Toh VV, Antrum JHG, Sloan B, Austin O, Muthayya P. Management of COVID-19 in burns patients: The experience of a UK burn centre. Burns. 2020 Jul;S0305417920304472. https://doi.org/10.1016/j.burns.2020.06.026 PMid:32713829 PMCid:PMC7333603

13. Ma S, Yuan Z, Peng Y, Chen J, Li H, Luo Q, et al. Experience and suggestion of medical practices for burns during the outbreak of COVID-19. Burns. 2020 Jun;46(4):749-55. https://doi.org/10.1016/j.burns.2020.03.014 PMid:32312568 PMCid:PMC7131295

14. Huang Z, Zhuang D, Xiong B, Deng DX, Li H, Lai W. Occupational exposure to SARS-CoV-2 in burns treatment during the COVID-19 epidemic: Specific diagnosis and treatment protocol. Biomed Pharmacother. 2020 Jul;127:110176. https://doi.org/10.1016/j.biopha.2020. 110176 PMid:32353825 PMCid:PMC7177133 
15. Kruchevsky D, Arraf M, Levanon S, Capucha T, Ramon Y, Ullmann Y. Trends in Burn Injuries in Northern Israel during the COVID-19 Lockdown. J Burn Care Res. 2020 Sep 10;iraa154. https://doi.org/10.1093/jbcr/iraa154 PMid:32914186 PMCid:PMC7499677

16. Williams FN, Nizamani R, Chrisco L, King BT. Increased Burn Center Admissions During COVID-19 Pandemic. J Burn Care Res. 2020 Sep 23;41(5):1128-1128. https:// doi.org/10.1093/jbcr/iraa112 PMid:32609342 PMCid:PMC 7337748

17. Azzena B, Perozzo FAG, De Lazzari A, Valotto G, Pontini A. Burn Unit admission and management protocol during COVID-19 pandemic. Burns [Internet]. 2020 Oct 3 [cited 2020 Oct 27]; Available from: http://www.sciencedirect.com/ science/article/pii/S0305417920305258

18. Khan T, Wani A, Darzi M, Bijli A. Epidemiology of burn patients in a tertiary care hospital in Kashmir: A prospective study. Indian J Burns. 2014;22(1):98. https://doi.org/ 10.4103/0971-653X.147017

19. Chauhan N, Kumar S, Sharma U. Proûle of acute thermal burn admissions to the intensive care unit of a tertiary burn care center in India. Indian J Burns. 2012;20(1):4. https:// doi.org/10.4103/0971-653X.111791

20. Karki B, Rai SM, Nakarmi KK, Basnet SJ, Magar MG, Nagarkoti KK, et al. Clinical Epidemiology of Acute Burn Injuries at Nepal Cleft and Burn Centre, Kathmandu, Nepal. Ann Plast Surg. 2018 Mar;80(3):S95. https://doi.org/ 10.1097/SAP.0000000000001270 PMid:29319567

21. Mehta K, Stewart BT, Pham TN, Nakarmi KK. 19 Epidemiology of Acute Burn Admissions at a Referral Center in Nepal: A Comparison Between Direct Admissions and External Referrals. J Burn Care Res. 2020;41(Supplement_1):S15-S16. https://doi.org/10.1093/ jbcr/iraa024.023

22. Shanmugakrishnan RR, Narayanan V, Thirumalaikolundusubramanian P. Epidemiology of burns in a teaching hospital in south India. Indian J Plast Surg Off Publ Assoc Plast Surg India. 2008;41(1):34-7. https://doi.org/10.4103/09700358.41108 PMid:19753198 PMCid:PMC2739549

23. Akther J, Nerker NE, Reddy PS, Khan M, Chauhan M, Shahapurkar VV. Epidemiology of Burned Patients Admitted In Burn Unit of A Rural Tertiary Teaching Hospital [Internet]. undefined. 2010 [cited 2020 Oct 27]. Available from: /paper/Epidemiology-of-Burned-Patients-AdmittedIn-Burn-of-Akther-Nerker/5efb99ac3521315d9387bdc $46 \mathrm{dc} 8 \mathrm{c} 083585 \mathrm{ea} 51 \mathrm{e}$

24. Saha S, Kumar A, Dash S, Singhal M. Managing Burns During COVID-19 Outbreak. J Burn Care Res. 2020 Sep 23;41(5):1033-6. https://doi.org/10.1093/jbcr/iraa086 PMid:32473015 PMCid:PMC7313996

25. Giusti EM, Pedroli E, D’Aniello GE, Stramba Badiale C, Pietrabissa G, Manna C, et al. The Psychological Impact of the COVID-19 Outbreak on Health Professionals: A Cross-Sectional Study. Front Psychol. 2020 Jul 10;11:1684. https://doi.org/10.3389/fpsyg.2020.01684 PMid:32754102 PMCid:PMC7366071

26. Li Y, Wang Y, Jiang J, Valdimarsdóttir UA, Fall K, Fang F, et al. Psychological distress among health professional students during the COVID-19 outbreak. Psychol Med. 2020 May 11;1-3. https://doi.org/10.1017/S0033291720001555 PMid:32389148 PMCid:PMC7225209

27. Shaukat N, Ali DM, Razzak J. Physical and mental health impacts of COVID-19 on healthcare workers: a scoping review. Int J Emerg Med. 2020 Dec;13(1):40. https:// doi.org/10.1186/s12245-020-00299-5 PMid:32689925 PMCid:PMC7370263

28. Galbraith N, Boyda D, McFeeters D, Hassan T. The mental health of doctors during the COVID-19 pandemic. BJPsych Bull. 2020 Apr 28;1-4. https://doi.org/10.1192/bjb.2020.44 PMid:32340645 PMCid:PMC7322151

29. Roy D, Tripathy S, Kar SK, Sharma N, Verma SK, Kaushal V. Study of knowledge, attitude, anxiety \& perceived mental healthcare need in Indian population during COVID-19 pandemic. Asian J Psychiatry. 2020 Jun;51:102083. https:/ /doi.org/10.1016/j.ajp.2020.102083 PMid:32283510 PMCid:PMC 7139237

30. Labrague LJ, Santos JAA. Fear of COVID 19, psychological distress, work satisfaction and turnover intention among frontline nurses. J Nurs Manag. 2020 Oct 11;jonm.13168. https://doi.org/10.21203/rs.3.rs-35366/v1

31. Shanafelt T, Ripp J, Trockel M. Understanding and Addressing Sources of Anxiety Among Health Care Professionals During the COVID-19 Pandemic. JAMA. 2020 Jun 2;323(21):2133. https://doi.org/10.1001/ jama.2020.5893 PMid:32259193

32. Lepelletier D, Grandbastien B, Romano-Bertrand S, Aho S, Chidiac C, Géhanno J-F, et al. What face mask for what use in the context of the COVID-19 pandemic? The French guidelines. J Hosp Infect. 2020 Jul;105(3):414-8. https:// doi.org/10.1016/j.jhin.2020.04.036 PMid:32348833 PMCid:PMC7194956

33. Choudhury ZH. ENTREPRENEURIAL ECOSYSTEMS: RECYCLING GLOVES DURING COVID-19 [Internet]. Open Science Framework; 2020 Jun [cited 2020 Oct 13]. Available from: https://osf.io/8nqxt https://doi.org/ 10.31219/osf.io/8nqxt

34. Blumenthal D, Fowler EJ, Abrams M, Collins SR. Covid-19 - Implications for the Health Care System. N Engl J Med. 2020;6. https://doi.org/10.1056/NEJMsb2021088 PMid:32706956

35. Colenda CC, Applegate WB, Reifler BV, Ii DGB. COVID19: Financial Stress Test for Academic Medical Centers. Acad Med. :3.

36. Khullar D, Bond AM, Schpero WL. COVID-19 and the Financial Health of US Hospitals. JAMA. 2020 Jun 2;323(21):2127. https://doi.org/10.1001/jama.2020.6269 PMid:32364565 